\title{
Selection of reference genes for quantitative real- time PCR expression studies of microdissected reproductive tissues in apomictic and sexual Boechera
}

\author{
Marco Pellino, Timothy F Sharbel, Martin Mau, Samuel Amiteye and José María Corral
}

\begin{abstract}
Background: Apomixis, a natural form of asexual seed production in plants, is considered to have great biotechnological potential for agriculture. It has been hypothesised that de-regulation of the sexual developmental pathway could trigger apomictic reproduction. The genus Boechera represents an interesting model system for understanding apomixis, having both sexual and apomictic genotypes at the diploid level. Quantitative qRT-PCR is the most extensively used method for validating genome-wide gene expression analyses, but in order to obtain reliable results, suitable reference genes are necessary. In this work we have evaluated six potential reference genes isolated from a 454 (FLX) derived cDNA library of Boechera. RNA from live microdissected ovules and anthers at different developmental stages, as well as vegetative tissues of apomictic and sexual Boechera, were used to validate the candidates.
\end{abstract}

Results: Based on homologies with Arabidopsis, six genes were selected from a 454 cDNA library of Boechera: RPS18 (Ribosomal sub protein 18), Efalpha1 (Elongation factor 1 alpha), ACT 2 (Actin2), UBQ (polyubiquitin), PEX4 (Peroxisomal ubiquitin conjugating enzyme) and At1g09770.1 (Arabidopsis thaliana cell division cycle 5). Total RNA was extracted from 17 different tissues, QRT-PCRs were performed, and raw Ct values were analyzed for primer efficiencies and gene ratios. The geNorm and normFinder applications were used for selecting the most stable genes among all tissues and specific tissue groups (ovule, anthers and vegetative tissues) in both apomictic and sexual plants separately. Our results show that BoechRPS18, BoechEfa 1, BoechACT2 and BoechUBQ were the most stable genes. Based on geNorm, the combinations of BoechRPS18 and BoechEfa 1 or BoechUBQ and BoechEfa 1 were the most stable in the apomictic plant, while BoechRPS18 and BoechACT2 or BoechUBQ and BoechACT2 performed best in the sexual plant. When subgroups of tissue samples were analyzed, different optimal combinations were identified in sexual ovules (BoechUBQ and BoechEfa 1), in anthers from both reproductive systems (BoechACT2 and BoechEfa1), in apomictic vegetative tissues (BoechEfol 1 and BoechACT2) and sexual vegetative tissues (BoechRPS18 and BoechEfa 1). NormFinder ranked BoechACT2 as the most stable in the apomictic plant, while BoechRPS18 was the best in the sexual plant. The subgroups analysis identified the best gene for both apomictic and sexual ovules (BoechRPS18), for anthers from both reproductive system (BoechEfa 1) and for apomictic and vegetative tissues (BoechACT2 and BoechRPS18 respectively)

Conclusions: From a total of six tested genes, BoechRPS18, BoechEfa 1, BoechACT2 and BoechUBQ showed the best stability values. We furthermore provide detailed information for the accurate normalization of specific tissue gene expression analyses of apomictic and sexual Boechera.

\footnotetext{
* Correspondence: corral@ipk-gatersleben.de

Apomixis Research Group, Leibniz-Institute für Pflanzengenetik und Kulturpflanzenforschung (IPK), Corrensstraße 3, D-06466 Gatersleben, Germany
} 


\section{Background}

Sexual reproduction in plants is a highly regulated process in which meiosis and syngamy initiate embryo and seed development. Aberrations in any step typically lead to abortion of seed development [1]. In contrast, apomixis (asexual reproduction through seeds [2]) is an alternative reproductive strategy in which aberrations to normal sexual processes are viable [3], and is found naturally in more than 400 species. Compared to sexual reproduction, apomixis is characterized by three developmental steps: the production of a meiotically unreduced egg cell (apomeiosis), parthenogenetic development of this egg cell without fertilization, and production of a functional endosperm with (pseudogamy) or without (autonomous) fertilization of the binucleate central cell of the ovule [4]. Importantly, apomictic seeds have embryos which are genetically identical to the mother plant. Hence, the successful introgression of apomixis into crop plants would greatly facilitate the fixation and propagation of genetic heterozygosity and associated hybrid vigour over successive generations, and could significantly reduce costs associated with hybrid seed production [5]. The biotechnological potential of apomixis has thus raised tremendous research interest.

Apomixis has repeatedly evolved from sex, and while the evolutionary origin and molecular nature of apomixis remain enigmatic, various hypotheses regarding specific genetic mechanisms have been proposed. One possible mechanism is de-regulation in the timing of sexual reproductive genes or pathways [4]. The switch from sexual to apomictic reproduction has also been associated with gene dosage effects during endosperm development [6]. Furthermore, the global regulatory effects of polyploidy and hybridity, both of which characterize virtually all asexual plants (and parthenogenetic animals), have been proposed as possible triggers for the switch from sex to apomixis [4,7]. More specifically, hybridity has been hypothesized to induce asynchronous expression of sexual reproduction genes to lead to apomixis [7].

Understanding patterns of differentially expressed genes is crucial for disentangling the complex regulatory networks which characterize sexual and apomictic seed production. Advances in cell isolation methods, in conjunction with next generation sequencing technology, have enabled global comparisons of gene expression patterns between sexual and apomictic reproductive tissues, and have provided support for deregulation of reproductive pathways in the switch from sex to apomixis $[8,9]$. The analysis of gene expression, however, requires sensitive, precise, and reproducible measurements for particular mRNA sequences in specific tissues. In this regard, quantitative real-time PCR (qRT-PCR) is at present the most extensively used method for validating genomewide (e.g. microarray) expression data [10], due to its high sensitivity, specificity, and broad quantification range [11]. Although it is an extremely powerful technique, qRT-PCR requires strict normalization steps to compensate for several experimental variables that cannot be completely controlled (e.g. amount of starting material, enzymatic efficiency, differences in the transcription activity between cell or tissues) and which can influence reproducibility between experiments [12]. Accurate normalization of qRT-PCR results is thus essential for precise comparisons between samples. The standard approach for normalization of qRT-PCR data is the use of internal control or reference genes, often referred to as housekeeping genes (HKGs [13]). This class of genes encodes proteins that typically function in basic cell metabolism or maintenance, with constant expression levels and low levels of fluctuation between most tissues. Currently, the most common and welldescribed housekeeping genes used for the normalization of gene expression data include actin [14], glyceraldehyde-3-phosphate dehydrogenase (G3PDH [14]), ribosomal genes, cyclophilin, elongation factor 1 -a (Ef $\alpha 1$ [14-17] ), adenine phosphoribosyl transferase (aprt [18]) and tubulin [19]. Recently, Silveira et al. [20] established BbrizUBCE, BbrizE1F4A and BbrizEF1 as the best reference genes for analyses of sexual and apomictic ovary tissues of the monocotyledon Brachiaria. Many studies have shown that standard housekeeping genes used as internal standards for the quantification of mRNA expression can indeed vary with the experimental conditions [15,21,22]. A well-tested housekeeping gene showing significant expression stability in a plant species or tissue type might not show the same stability if used in different experimental situations, species or tissues $[13,15]$. Reference genes therefore need to be properly validated for specific species, tissue types or reproductive modes when designing quantitative gene expression studies [23]. Furthermore, the use of a single housekeeping gene for qRT-PCR normalization is not recommended due to potential error, and it has been proposed that at least two or three housekeeping genes should be used in parallel as internal standards $[12,21,24]$. Thus it is essential that prior validation of all reference genes is performed to confirm their expression stability in particular experimental conditions or tissues/ cells, in order to prevent inaccurate data interpretation and subsequent false conclusions.

The genus Boechera (Brassicacea) is becoming a model system for studying apomixis, being composed of both sexual and apomictic genotypes, the latter of which display quantitative variation for levels of apomictic seed production [3]. Importantly, the occurrence of diploid apomictic forms [25] in Boechera makes it possible to 
compare differences in gene expression between apomictic and sexual individuals without the concomitant effects of polyploidy. Moreover, as wild relatives of Arabidopsis thaliana, molecular genetic studies in Boechera are facilitated by the extensive genetic resources which have been developed for this model plant [26]. In addition, Boechera species have been used for comparative genomic analysis, including partial genome sequencing [27], genetic map construction [28] and transcriptome sequencing [8,9], and the entire genomes of B. stricta and $B$. divaricarpa are being sequenced (DOE Joint Genome Institute; http://www.jgi.doe.gov).

Considering the growing importance of this genus for evolutionary functional genomics, the aims of this work are to (1) validate the stability of some commonly used housekeeping genes, and (2) evaluate a new housekeeping gene for qRT-PCR analyses of microdissected reproductive tissues in apomictic and sexual members of the genus Boechera. We have identified one putative new HKG from our transcriptomic analyses of sexual and apomictic ovules at different developmental stages $[8,9]$, and have additionally tested five known HKGs from Arabidopsis and other plant genera [Actin 2, s18 rRNA, elongation factor 1- $\alpha$ (Ef $\alpha 1$ ), Pex 4 and Polyubiquitin 10; Table 1]. All HKGs were tested for stable gene expression patterns in both sexual and apomictic Boechera in various microdissected reproductive tissues including: four ovule stages (Figure 1; [9]), three anther stages (Figure 2; [29]) and four different tissues (flowers, leaves, roots, stems; Table 2).

\section{Results}

In order to identify optimal reference (HKG) genes in the genus Boechera, one candidate gene from a SuperSAGE dataset which was found to be uniformly expressed between apomictic and sexual Boechera accessions [8,9], and five previously-described HKGs (Actin 2, RPS18, Elongation factor $1-\alpha$, Pex 4 and UBQ) from
Arabidopsis [14] and other plant species [15] were selected. Using the Arabidopsis genome database, in addition to 2 flower-specific Boechera cDNA libraries $[8,9]$, we were able to design PCR primers in order to amplify, clone and sequence sections of the following six genes BoechACT2, BoechPEX4, BoechPEX4, BoechRPS18, BoechEfa 1, BoechAt1g09770.1 and Boechera Polyubiquitin 10 (Table 1).

The six candidate reference genes were evaluated for gene expression stability by qRT-PCR, using qRT-PCR primers designed in exonic regions from the cloned and sequenced Boechera homologues (Table 1). Based on cDNA analysis (not shown) and the dissociation curve (additional file 1) for each of the primer sets tested, a single PCR product with the expected size was amplified with HKG stability across both vegetative and microdissected reproductive tissues, and showed relatively tight Ct distributions for all 6 genes (Figure 3). Based upon the distribution of $\mathrm{Ct}$ values across different tissues, the HKGs could be split into low (BoechRPS18, BoechEfa1, BoechACT2 and BoechUBQ) and high (BoechAt1g09770.1 and BoechPEX4) values (Figure 3). Using the Miner algorithm [30], amplification efficiencies (E) were calculated to range between $0.74 \pm 0.03 \%$ and 1.01 $\pm 0.1 \%$. Expression ratios (R) were calculated, and amplification efficiencies and $\mathrm{Ct}$ values exported to the geNorm program as described by Vandesompele et al. [12] and normFinder program as described by Andersen et al. [31]. In order to evaluate gene stability, geNorm relies on the principle that two ideal control genes have the same expression ratio in all the samples despite cell type or experimental conditions. The program calculates two variables: the pairwise variation $(\mathrm{V})$, which indicates the minimum number of reference genes required for a precise normalization, and the average pairwise variation of a particular gene compared to that of all other genes (M). Genes with the lowest $M$ values have the most stable expression (Table 3). The normFinder program

Table 1 Boechera-specific qRT-PCT primers for tested HKGs

\begin{tabular}{|c|c|c|c|c|}
\hline $\begin{array}{l}\text { Gene identification/Gene } \\
\text { description }\end{array}$ & Primer sequence $5^{\prime}-3^{\prime}$ forward/reverse & $\begin{array}{c}\text { Amplicon } \\
\text { size (bp) }\end{array}$ & $\begin{array}{l}\text { Amplification } \\
\text { efficiency } \pm \text { SD * }\end{array}$ & $\begin{array}{l}\text { EMBL Accession } \\
\text { Number }\end{array}$ \\
\hline BoechACT2/Actin 2 & $\begin{array}{l}\text { GTTCCACCACTGAGCACAATGTTACC/ } \\
\text { AGTCTTGTTCCAGCCCTCTITGTG }\end{array}$ & 132 & $0.94 \pm 0.003$ & FR846456 \\
\hline BoechEF1/Elongation factor-1 alpha & $\begin{array}{l}\text { CCAAGGGTGAAAGCAAGGAGAGC/ } \\
\text { CACTGGTGGTITIGAGGCTGGTATCT }\end{array}$ & 75 & $0.96 \pm 0.002$ & FR846458 \\
\hline BoechRPS18/Ribosomal protein S18 & $\begin{array}{l}\text { GCTGGGGAGTTATCTGCTGCTGAG/ } \\
\text { CTTGCCGTCTTTGTAATCCTTCTGC }\end{array}$ & 117 & $0.94 \pm 0.003$ & FR846460 \\
\hline BoechPEX4/Peroxin 4 & $\begin{array}{l}\text { TTGGCAGTTGACAGTTGGATCTTGTTC/ } \\
\text { TCGCTCGTGATGCCTATTCATCATAC }\end{array}$ & 143 & $0.83 \pm 0.009$ & FR846459 \\
\hline $\begin{array}{l}\text { BoechAt1g09770.1/Arabidopsis thaliana } \\
\text { cell division cycle } 5\end{array}$ & $\begin{array}{l}\text { GCCATGATCTAAAAAGTTGGGACAAA/ } \\
\text { TATTCGTCACAACACATGCAAGGTITA }\end{array}$ & 145 & $0.88 \pm 0.007$ & FR846457 \\
\hline BoechUBQ/Polyubiquitine & $\begin{array}{l}\text { GGCTAAGATCCAGGACAAGGAAGGTAT/ } \\
\text { CTGGATGTTATAGTCAGCCAAAGTGCG }\end{array}$ & 71 & $\begin{array}{r}0.94 \pm 0.004 \\
n\end{array}$ & FR851958 \\
\hline
\end{tabular}




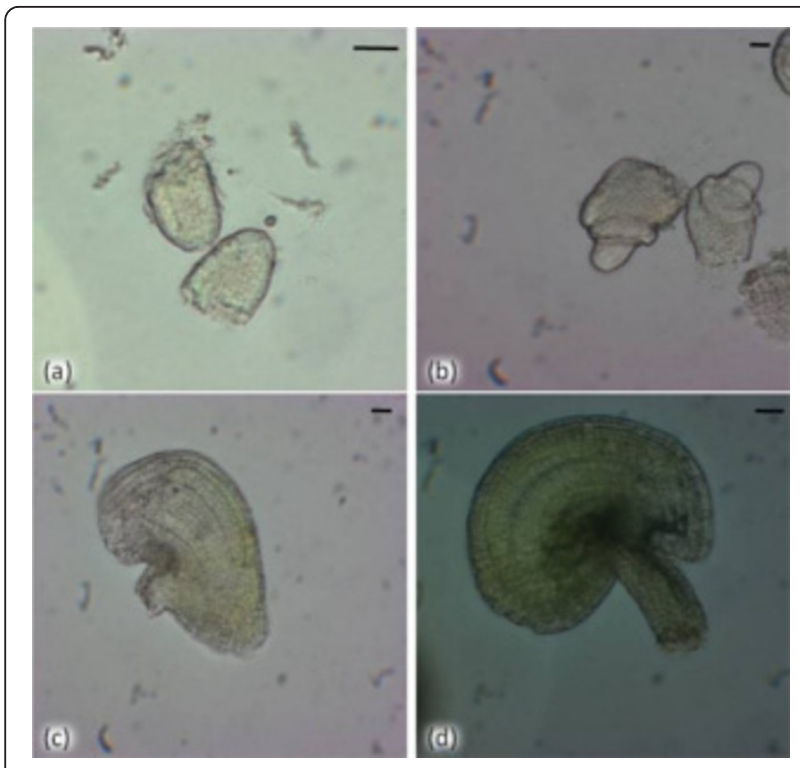

Figure 1 Live microdissected Boechera ovules at multiple developmental stages. (a) 11 to $1 \mathrm{Il}$; (b) 2II to 2IV; (c) 3II to 3III; (d) $3 \mathrm{~V}$ to $4 \mathrm{l}$ [38]. Bar $=10 \mu \mathrm{m}$.

uses a model-based approach to select the genes with the minimum expression variation over the sample. Every gene is ranked with a stability value based on the intragroup variance and, if applicable, on the intergroup variance

The results based on geNorm show that three genes, BoechRPS18, BoechACT2 and BoechEf $\alpha 1$, are the most stable in all tissues of both the apomictic and sexual accessions (Figure 4). The pairwise variation (V) values showed that for accurate normalisation, the two most suitable stable genes to employ are BoechRPS18 and BoechEf $\alpha 1$ for the apomictic accession, and BoechRPS18 and BoechAct 2 for the sexual accession. With the addition of one more gene, pairwise variation (V2/3) values of 0.042 for the apomictic and 0.078 for the sexual accessions were obtained (Figure 5), values far below the cut-off of 0.15 suggested by Vandesompele et al. [12].

NormFinder ranked, for the apomictic accession, BoechACT2 and BoechEf $\alpha 1$ as the best genes with stability

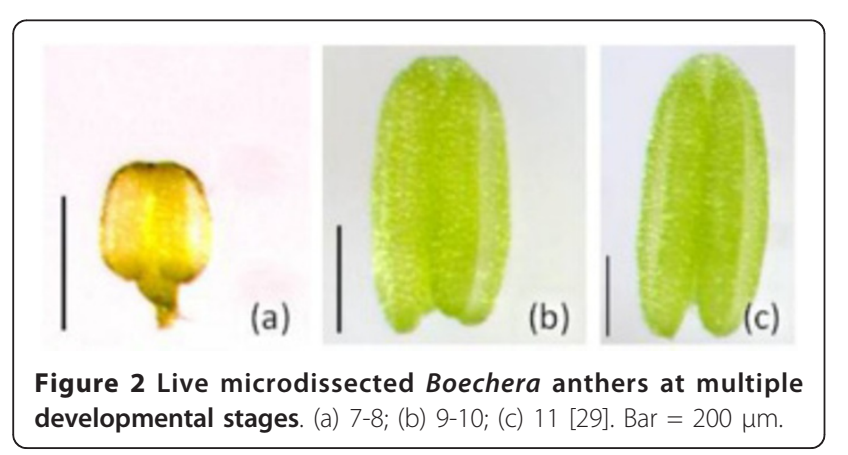

values of 0.070 and 0.094 respectively, and BoechRPS18 as the third best gene with a stability value of 0.095 . For the sexual accession BoechRPS18 and BoechAct2 with stability values of 0.109 and 0.123 respectively were ranked as the most stable genes (Figure 6) in accordance with the result from geNorm.

In order to identify the best reference gene suitable for specific tissues, separate analyses were performed independently for vegetative tissues, and microdissected live ovules (all stages) and anthers (all stages; Table 2). As expected, BoechRPS18, BoechACT2 and BoechEf $\alpha 1$ again exhibited high stability, but interestingly, based on geNorm, the stability values varied between tissue groups (Table 3 ). To validate this result, the analyses were repeated, but this time the two least stable genes (BoechPEX4 and BoechAt1g09770.1) were removed from the set. In doing so, similar stability values (i.e. no effect on M) for BoechRPS18, BoechACT2 and BoechEfa1 to those observed in the earlier analyses were obtained. In the subsequent analysis, normFinder confirmed the three candidates as the most stable ones. In 5 specific tissues the most stable ranked gene had also exhibited high stability using geNorm, and in only a single case one of the 2 best genes from geNorm were ranked as second and third by normFinder (Table 4). These data thus showed that BoechRPS18, BoechACT2 and BoechEf $\alpha 1$ provide the best combination of HKGs for any tissue specific normalisation in Boechera.

Further analyses were done to identify the two best HKGs common to both apomictic and sexual reproductive modes. In removing Ef $\alpha 1$ from the gene set of the apomictic accession, geNorm identified BoechRPS18 and BoechACT2 as the most stable genes with $\mathrm{M}=0.24$ and $\mathrm{V} 2 / 3=0.073$, a result was also confirmed by NormFinder. In this case all samples were divided into two groups according to reproductive mode and analyzed simultaneously in order to find the best genes throughout all samples. BoechRPS18 and BoechACT2 were the most stable genes with stability values of 0.054 and 0.078. BoechRPS18 and BoechACT2 can therefore be used independently of reproductive mode, and should be chosen in cases where the reproductive mode of the plant under study is uncertain.

To ascertain the stability and suitability of Ubiquitin (BoechUBQ) in all tissues of Boechera, the $\mathrm{R}$ values of all test genes were recalculated with BoechRPS18 as control, and analysed. As expected geNorm showed BoechUBQ to be the most stable gene in both apomictic ( $M$ $=0.11)$ and sexual $(\mathrm{M}=0.20)$ Boechera. Based upon calculations of $\mathrm{V}$, the data reported here show that BoechUBQ and BoechEf $\alpha 1$ (V2/3 = 0.12) provide accurate normalisation for apomictic genotypes, whereas BoechUBQ and BoechAct2 (V2/3 = 0.10) are more appropriate for sexual Boechera. NormFinder instead ranked 
Table 2 Boechera accessions, including ovule and anther stage-specific developmental characteristics

\begin{tabular}{|c|c|c|c|c|c|c|c|}
\hline Species $^{a}$ & ID & Collection locality & Reproduction $^{\mathbf{b}}$ & $\begin{array}{l}\text { Ovule-anther } \\
\text { stage }^{c}\end{array}$ & Ovule development $^{d}$ & $\begin{array}{l}\text { Anther } \\
\text { stage }^{g}\end{array}$ & $\begin{array}{c}\text { Anther } \\
\text { development }\end{array}$ \\
\hline \multirow[t]{4}{*}{ B. stricta } & MT49 & $\begin{array}{c}\text { Sagebrush Meadow, } \\
\text { MT }\end{array}$ & Sex & a & Nucellus & $7-8$ & Premeiotic PMC \\
\hline & & & & $b$ & $M M C^{e}$ formation & $9-10$ & Meiotic PMC ${ }^{f}$ \\
\hline & & & & c & $\begin{array}{c}\text { Tetrad to } \\
\text { degeneration }\end{array}$ & 11 & Microspore formation \\
\hline & & & & $d$ & Fertilised ovules & & \\
\hline \multirow{4}{*}{$\begin{array}{c}\text { B. } \\
\text { divaricarpa }\end{array}$} & MT15 & Vipond Park, MT & Apomixis & a & Nucellus & $7-8$ & Premeiotic PMC \\
\hline & & & & $b$ & $M M C^{e}$ formation & $9-10$ & Meiotic PMC \\
\hline & & & & c & $\begin{array}{l}\text { Tetrad to } \\
\text { degeneration }\end{array}$ & 11 & Microspore formation \\
\hline & & & & $d$ & Fertilized ovules & & \\
\hline
\end{tabular}

a Species identification were based upon silique orientation, trichome morphology, and cpDNA sequences [40]

${ }^{\mathrm{b}}$ Reproductive mode was confirmed using the flow cytometric seed screen $[8,41]$

c See Figures 1 and 2 for images of each stage.

${ }^{d}$ According to Schneitz et al [38]

e MMC: Megaspore mother cell

$f$ PMC: Pollen mother cell stage

${ }^{g}$ According to Armstrong et al.[29]

BoechUBQ as third best gene (stability value $=0.194$ ) for the apomictic plant and the second best (stability value $=0.065)$ for the sexual.

\section{Discussion}

Based upon the transcriptional profiles of the 6 housekeeping genes tested in this study, and geNorm and normFinder analyses of different vegetative and reproductive tissues of sexual and apomictic Boechera, we conclude that ribosomal subunit protein 18 (BoechRPS18), elongation factor-1 (BoechEfa1), Actin 2 (BoechACT2) and Polyubiquitine (BoechUBQ) are the most stable. Although all 4 genes show significant stability, their values $(M)$ varied depending on either specific tissue and/or reproductive system. Considering these criteria and pairwise variation $(\mathrm{V})$, we propose optimal

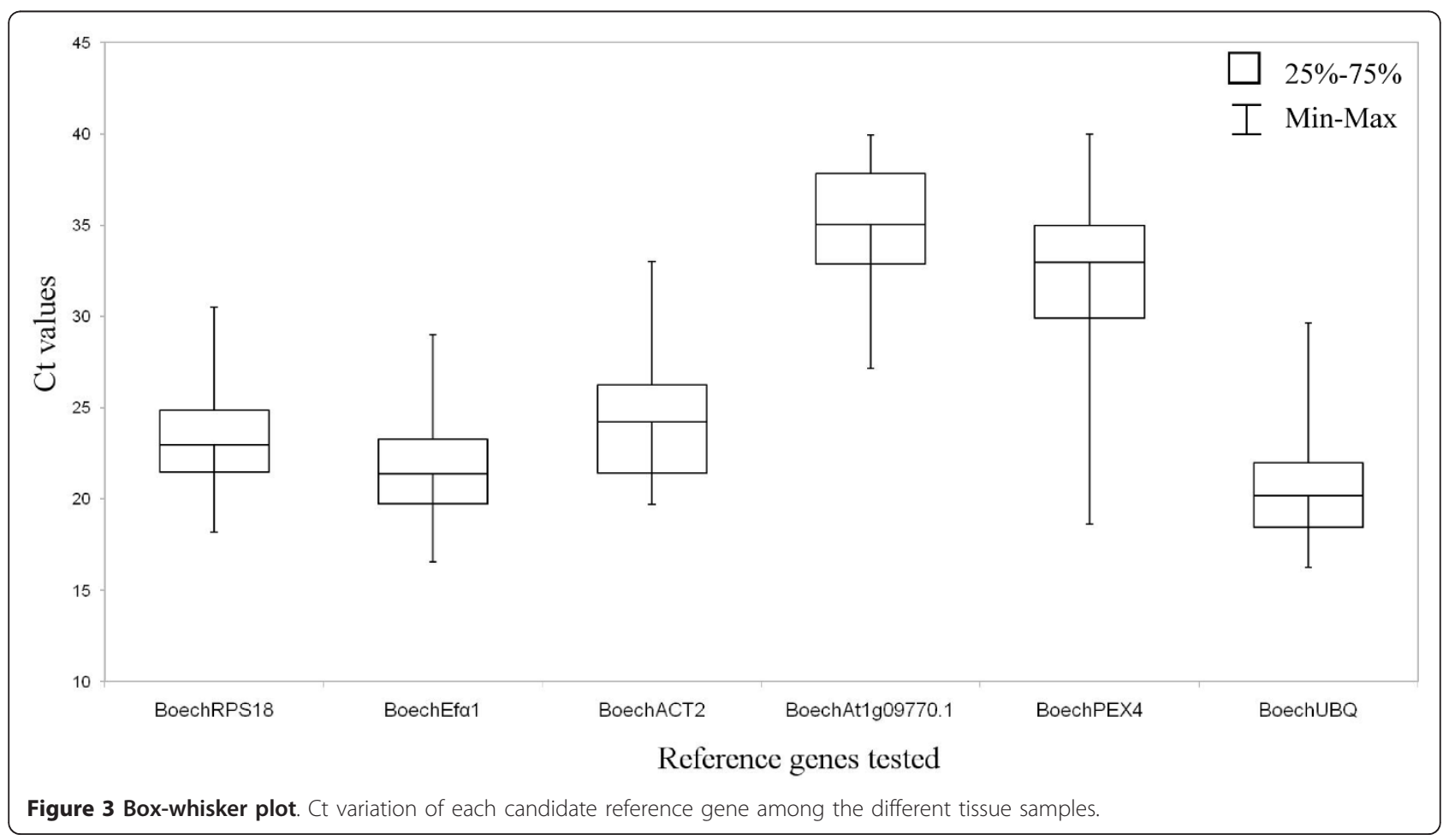


Table 3 Summary of the 2 best HKG combinations for different tissues and reproductive system according to geNorm

\begin{tabular}{|c|c|c|c|c|c|c|}
\hline Tissue & $\begin{array}{l}\text { Recommended } \\
\text { HKGs }\end{array}$ & $\begin{array}{c}M \\
\text { values }\end{array}$ & $\begin{array}{l}\text { V2/3 } \\
\text { values }\end{array}$ & $\begin{array}{l}\text { Recommended HKGs (BoechRPS18 replaced by } \\
\text { UBQ) }\end{array}$ & $\begin{array}{c}M \\
\text { values }\end{array}$ & $\begin{array}{l}\mathrm{V} 2 / 3 \\
\text { values }\end{array}$ \\
\hline Apo all tissues & $\begin{array}{c}\text { BoechRPS18 } \\
\text { BoechEf } \alpha 1\end{array}$ & 0.130 & 0.042 & BoechUBQ BoechEfo 1 & 0.120 & 0.120 \\
\hline $\begin{array}{l}\text { Apo vegetative } \\
\text { tissues }\end{array}$ & BoechEf $\alpha 1$ BoechACT2 & 0.170 & 0.007 & BoechUBQ BoechEf $\alpha 1$ & 0.220 & 0.120 \\
\hline Apo ovules & $\begin{array}{l}\text { BoechRPS18 } \\
\text { BoechEfa } 1\end{array}$ & 0.060 & 0.040 & BoechUBQ BoechEf $\alpha 1$ & 0.055 & 0.131 \\
\hline Apo anthers & BoechACT2 BoechEfa 1 & 0.020 & 0.001 & BoechACT2 BoechEf $\alpha 1$ & 0.020 & 0.090 \\
\hline Sex all tissues & $\begin{array}{l}\text { BoechRPS18 } \\
\text { BoechACT2 }\end{array}$ & 0.017 & 0.078 & BoechUBQ BoechACT2 & 0.200 & 0.100 \\
\hline $\begin{array}{l}\text { Sex vegetative } \\
\text { tissues }\end{array}$ & $\begin{array}{l}\text { BoechRPS18 } \\
\text { BoechEf } 1\end{array}$ & 0.070 & 0.089 & BoechUBQ BoechACT2 & 0.220 & 0.100 \\
\hline Sex ovules & $\begin{array}{l}\text { BoechRPS18 } \\
\text { BoechACT2 }\end{array}$ & 0.010 & 0.088 & BoechUBQ BoechEf $\alpha 1$ & 0.010 & 0.057 \\
\hline Sex anthers & BoechEfa 1 BoechACT2 & 0.001 & 0.025 & BoechEfa 1 BoechACT2 & 0.001 & 0.016 \\
\hline
\end{tabular}

combinations of reference genes for normalization of gene expression data in transcriptome analyses of different tissues (Table 3). Using normFinder we were able to verify the stability of our candidates by using a different algorithm. Interestingly, in 11 analyses out of 16, the first HKG to be ranked as most stable by NormFinder was also found in the best combination provided by

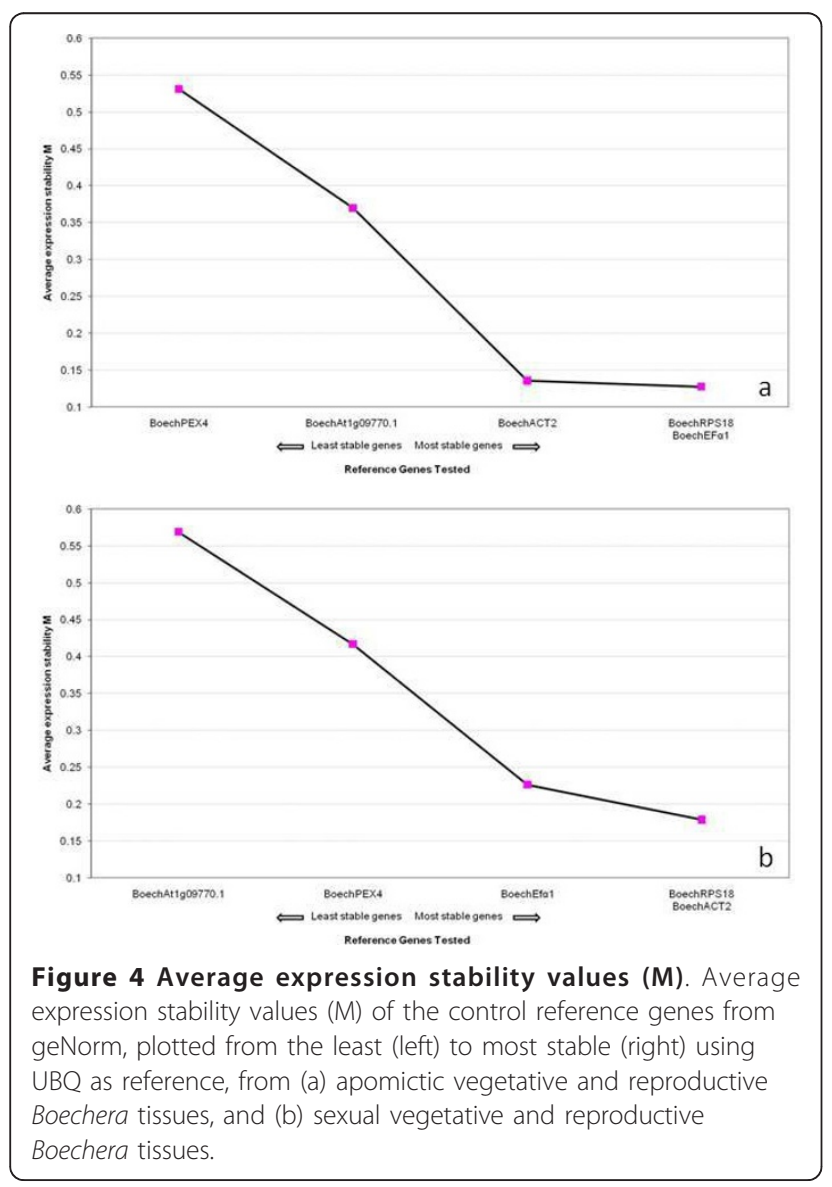

geNorm. In 5 cases the second best HKG to be ranked by normFinder was included in the best couple provided by geNorm, while the remaining one was ranked as the third best. These discrepancies could be explained by the fact that geNorm and normFinder use two different algorithms for the evaluation of the best HKGs. geNorm provides the two genes that have the most similar expression profiles through a stepwise elimination of the

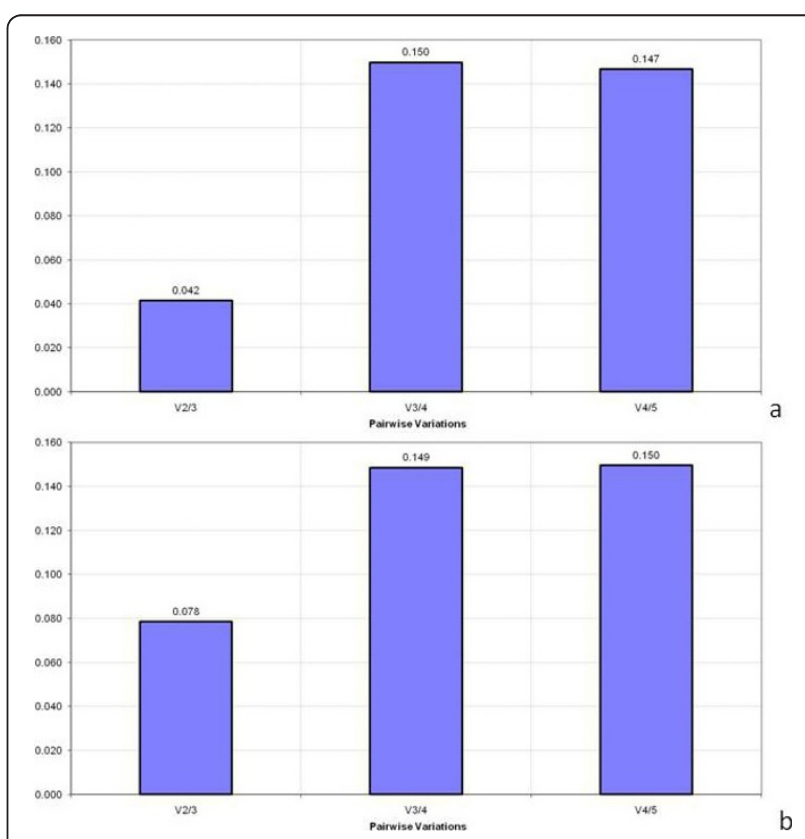

Figure 5 Pairwise variation (V). Pairwise variation (V) of the selected reference genes in (a) apomictic and (b) sexual Boechera, as calculated from geNorm, from the most to least stable $M$ values: (a) V2/3 - pairwise variation between the 2 most stable genes (RPS18 and Ef $\alpha 1$ ) + the third most stable gene (Act2), V3/4 addition of the fourth most stable gene (at1g09770.1), V4/5 addition of the fifth most stable gene (Pex4); (b) V2/3 - RPS18, Act2 plus Efa1, V3/4 - plus Pex4, V4/5 - plus at1g09770.1. 

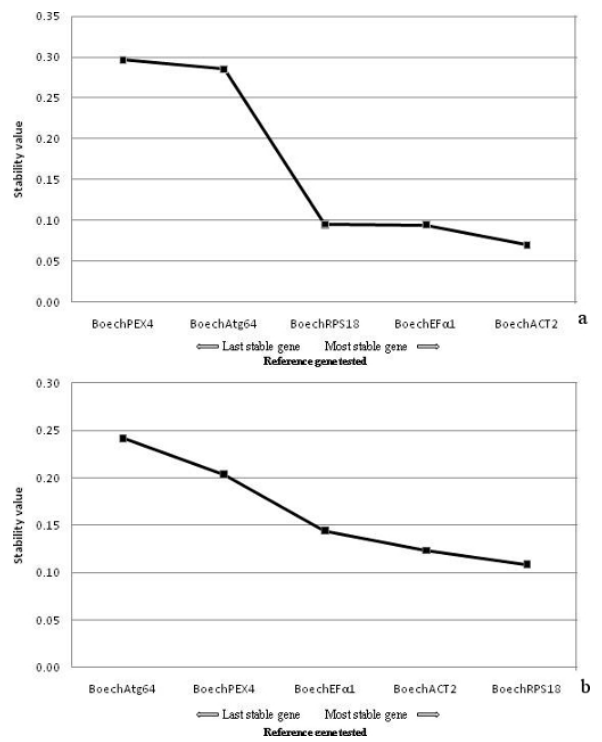

Figure 6 NormFinder stability values. Stability values of the control reference genes from normFinder, plotted from the least (left) to most stable (right) using UBQ as reference, from (a) apomictic vegetative and reproductive Boechera tissues, and (b) sexual vegetative and reproductive Boechera tissues.

least stable genes in the sample, while normFinder instead uses a model-based approach to calculate a stability value which represents the expression variation of the gene throughout the sample. Differences in ranking when using these two programs have previously been found (see [32,33]). Considering the errors that could result from single HKG normalization strategy [12] and that at least one gene from the best couple identified by geNorm was always ranked in the first 2 positions by normFinder, we suggest using the specific pair of genes recommended by geNorm (Table 3). As validation for our choice of genes, the best couples of HKGs (according to geNorm) were chosen for normalizing the expression of 4 SuperSAGE tags that had previously showed reproduction specific expression between 2 ovule developmental stages in Boechera. qRT-PCR were performed and the relative expression of the 4 tags was normalized against BoechRPS18, BoechACT2 and BoechEf $\alpha 1$ in the best combination according to geNorm, using the REST2009 software [34]. The result of the normalization was consistent with the SuperSAGE expression data (See additional file 2). We hypothesize that interactions between the 4 best housekeeping genes identified here are minimized since each is involved in independent cellular processes.

\section{Conclusions}

This work is the first in depth analysis of reference genes in a dicot plant with both sexual and apomictic reproductive forms (Boechera) and, more importantly, the first report of a housekeeping gene analysis on live microdissected ovules and anthers. These data provide an important tool for transcriptomal analyses of reproductive tissues in Boechera, an excellent model system for the study of apomixis.

\section{Methods}

Two Boechera accessions, a sexual diploid B. stricta and a facultative apomictic diploid $B$. divaricarpa were selected for the analyses (Table 2). Seedlings of these accessions were grown and maintained in a phytotron at the IPK under controlled environmental conditions (day: $16 \mathrm{~h}, 21^{\circ} \mathrm{C}$; night: $8 \mathrm{~h}, 16^{\circ} \mathrm{C}$; humidity $70 \%$ ).

Table 4 Summary of the 2 best HKG combinations for different tissues and reproductive system according to normFinder

\begin{tabular}{|c|c|c|c|c|}
\hline Tissue & Recommended HKGs & Stability values & Recommended HKGs, (BoechRPS18 replaced by UBQ) & Stability values \\
\hline \multirow[t]{2}{*}{ Apo all tissues } & BoechACT2 & 0.07 & BoechACT2 & 0.085 \\
\hline & BoechEf $\alpha 1$ & 0.094 & BoechEf $\alpha 1$ & 0.188 \\
\hline \multirow[t]{2}{*}{ Apo vegetative tissues } & BoechACT2 & 0.073 & BoechACT2 & 0.22 \\
\hline & BoechEf $\alpha 1$ & 0.105 & BoechEf $\alpha 1$ & 0.116 \\
\hline \multirow[t]{2}{*}{ Apo ovules } & BoechRPS18 & 0.015 & BoechEf $\alpha 1$ & 0.014 \\
\hline & BoechEf $\alpha 1$ & 0.015 & BoechUBQ & 0.082 \\
\hline \multirow[t]{2}{*}{ Apo anthers } & BoechACT2 & 0.007 & BoechEf $\alpha 1$ & 0.106 \\
\hline & BoechEf $\alpha 1$ & 0.007 & BoechACT2 & 0.108 \\
\hline \multirow[t]{2}{*}{ Sex all tissues } & BoechRPS18 & 0.109 & BoechACT2 & 0.053 \\
\hline & BoechACT2 & 0.123 & BoechUBQ & 0.065 \\
\hline \multirow[t]{2}{*}{ Sex vegetative tissues } & BoechRPS18 & 0.014 & Boech ACT2 & 0.13 \\
\hline & BoechEf $\alpha 1$ & 0.015 & BoechEf $\alpha 1$ & 0.134 \\
\hline \multirow[t]{2}{*}{ Sex ovules } & BoechRPS18 & 0.01 & BoechEf $\alpha 1$ & 0.008 \\
\hline & BoechACT2 & 0.151 & BoechACT2 & 0.039 \\
\hline \multirow[t]{2}{*}{ Sex anthers } & BoechEf $\alpha 1$ & 0.001 & BoechEfa 1 & 0.086 \\
\hline & BoechACT2 & 0.001 & BoechACT2 & 0.088 \\
\hline
\end{tabular}


Six candidate housekeeping genes were selected, 5 previously-described HKGs in other plant genera and 1 new HKG which appeared to be stably expressed in a SuperSAGE dataset (Table $1 ;[8,9]$ ). The gene to which the selected SuperSAGE tag sequence corresponded was found via a BLAST search [35] to two flower-specific (sexual and apomictic) Boechera cDNA libraries which were sequenced using 454 (FLX) technology [8]. The corresponding Boechera cDNA (Polyubiquitine, Table 1) was annotated using a homology search to the Arabidopsis genome (http://www.arabidopsis.org). Arabidopsis homologues to the 5 known HKG's were similarly identified, and these were BLASTed [35] to the Boechera cDNA libraries (E-value $<3 e-024$ and 2e-019 for the apomictic and sexual $454 \mathrm{cDNAs}$ respectively) to obtain corresponding Boechera-specific gene sequences. PCR primers were then designed for DNA sequencing of the identified genes using DNASTAR Lasergene ${ }^{\circledR}$ Primer Select (http://www.dnastar.com/products/lasergene.php).

DNA was extracted from $100 \mathrm{mg}$ of leaf tissue from each plant using a Qiagen Dneasy ${ }^{\circledR}$ Plant Mini Kit (QIAGEN, Hilden, DE) according to the manufacturer's instructions. For all HKGs, PCR reactions $(10 \mu \mathrm{l})$ were mixed as follows: $25 \mathrm{ng}$ of DNA, $1 \mu \mathrm{l}$ of PCR Buffer II, 10 pmol for each primer, $0.025 \mathrm{U}$ of AccuPrime ${ }^{\mathrm{TM}} \mathrm{Taq}$ DNA Polymerase High Fidelity (Invitrogen, Carlsbad, CA) with $3.5 \mathrm{mM}$ of $\mathrm{MgCl}_{2}$ and $4.95 \mu \mathrm{l}$ of $\mathrm{H}_{2} \mathrm{O}$. PCR reactions were performed in a Mastercycler ep384 (Eppendorf, Hamburg, DE) using the following touchdown thermal cycling profile: $94^{\circ}$ for $10 \mathrm{~min}$; 9 cycles of $94^{\circ}$ for $15 \mathrm{sec}, 65^{\circ}$ for $15 \mathrm{sec}$ (1 degree decrease in temperature every cycle with a final temperature of $\left.54^{\circ}\right), 72^{\circ}$ for $30 \mathrm{sec}$; 35 cycles of $94^{\circ}$ for $30 \mathrm{sec}, 57^{\circ}$ for $15 \mathrm{sec}, 68^{\circ}$ for $2 \mathrm{~min} 30 \mathrm{sec}$; and a final $68^{\circ}$ for $15 \mathrm{~min}$. Each PCR product was cloned into a TOPO TA Cloning ${ }^{\circledR}$ (Invitrogen) vector according to the recommendation of the supplier. Eight clones per product were confirmed by DNA sequencing using Sanger Sequencing methods on an ABI 3730 xL platform (Applied Biosystem. Carlsbad, California) and analyzed using the DNASTAR Lasergene $^{\circledR}$ SeqBuilder and MegAlign programs.

qRT-PCR Primers were designed using DNASTAR Lasergene ${ }^{\circledR}$ PrimerSelect, with all amplification products targeted between 70 and $160 \mathrm{bp}$, and melting temperatures between $58^{\circ}$ to $63^{\circ} \mathrm{C}$. The newly-designed primers were checked using the following PCR $(20 \mu \mathrm{l})$ protocol: $25 \mu \mathrm{g}$ of genomic DNA, $2 \mu \mathrm{l}$ of $10 \mathrm{x}$ reaction buffer, 20 pmol for each primer, $0.5 \mathrm{u} / \mu \mathrm{l}$ of BioTAQ DNA Polymerase (Bioline $\mathrm{GmbH}$, Luckenwalde, DE), $2.5 \mathrm{nM}$ of dNTPs, $2 \mathrm{mM}$ of $\mathrm{MgCl}_{2}, 11.1 \mu \mathrm{l}$ of water. We used the following thermal cycling profile: $94^{\circ} \mathrm{C}$ for $3 \mathrm{~min}, 35$ cycles of $94^{\circ} \mathrm{C}$ for $30 \mathrm{sec}, 59^{\circ} \mathrm{C}$ for $15 \mathrm{sec}, 68^{\circ} \mathrm{C}$ for 1 min and finally $70^{\circ} \mathrm{C}$ for $7 \mathrm{~min}$. The size of all PCR products was verified on a $1.5 \%$ agarose gel.
Total RNA was isolated from 4 different tissues (leaf, root, stem and flower) harvested from 2 biological replicates of both Boechera accessions (Table 2) using the Qiagen Rneasy $\left.{ }^{(}\right)$Plant Mini Kit following the manufacturer's instructions. The isolated RNA was treated with Qiagen Rnase-Free DNase according to the producer's protocol in order to eliminate any contaminating traces of DNA. A second purification step was performed using a Qiagen ${ }^{\circledR}$ Rneasy Mini Kit to eliminate contaminating polysaccharides, proteins and the DNase enzyme. The final concentration and quality was checked using an Agilent Technologies 2100 Bioanalyzer NanoChip (Agilent Technologies, - Santa Clara, CA, United States).

The gynoecia of sexual and apomictic Boechera were dissected from flowers at the megasporogenesis stage in a $0.55 \mathrm{M}$ sterile mannitol solution between 7:30 am and 9:00 am each day. Microdissection was performed in a sterile laminar air flow cabinet under a stereoscopic microscope (Stemi 1000; Carl Zeiss). Ovules at 4 different developmental stages (Table 2 and Figure 1) and placental tissues were then collected under an inverted microscope (Axiovert $200 \mathrm{M}$; Carl Zeiss), in sterile conditions using sterile glass needles (self made using Narishige PC-10 puller). For each developmental stage approximately 20 ovules and $1 \mathrm{~mm}^{2}$ of ovary tissue were collected in separate sterile Eppendorf tubes containing $200 \mu \mathrm{l}$ of RNA stabilizing buffer, using a glass capillary (internal diameter $150 \mu \mathrm{m}$ ) interfaced to an Eppendorf Cell Tram Vario. Anthers at corresponding flower developmental stages 8-10 [29] (Figure 2) were selected for extraction of total RNA. Approximately 30 anther heads per sample were dissected from fresh whole flower buds and stored in RNA stabilizing buffer (RNA later; Sigma-Aldrich) under a stereoscopic microscope (Zeiss Stereo Discovery V12) using sterile glass needles. RNA was extracted using a Qiagen PicoPure Isolation Kit and purified of contaminating DNA using Qiagen RNase-Free DNase.

First strand cDNA was synthesised from $10 \mathrm{ng}$ starting RNA with a RevertAid ${ }^{\mathrm{TM}} \mathrm{H}$ Minus First Strand cDNA Synthesis Kit (Fermentas) using an oligo(dT)18 primer following the manufacturer's instructions. The resultant concentration was checked using a PicoGreen ${ }^{\circledR}$ dsDNA Quantitation Kit (Invitrogen) with a NanoDrop ${ }^{\circledR}$ ND-3300 Spectrofluorometer (NanoDrop). qRT-PCR reactions were performed on an ABI-PRISM $7700 \mathrm{HT}$ FAST Real-Time PCR System (Applied Biosystems) with the following cycling profile: $50^{\circ} \mathrm{C}$ for $2 \mathrm{~min}, 95^{\circ} \mathrm{C}$ for 10 min; 40 cycles of $95^{\circ} \mathrm{C}$ for $15 \mathrm{sec}, 60^{\circ} \mathrm{C}$ for 1 minute. 10 $\mu \mathrm{l}$ reactions were performed using the following master mix: $5 \mu$ l of SYBR I Master Mix buffer, a total of 16.6 pmol for both sense and anti-sense primers, $2.5 \mu \mathrm{l}$ of water and $1.5 \mu \mathrm{l}$ of cDNA. A melting curve gradient was obtained from the product at the end of the 
amplification for checking amplicon quality. cDNA samples derived from somatic tissues (leaf, root, stem and flower) were run in a serial dilution range of 5, 2.5, 1.25, 0.625 and $0.312 \mathrm{ng}$. All samples were run in triplicate with the control gene included in each plate. Due to low amounts of starting cDNA material from the micro-dissected ovules, a dilution range of $1,0.5,0.25,0.125$, $0.062 \mathrm{ng}$ was used. Candidate and control genes were run simultaneously in two replicates with 4 ovule stages and 3 anther head stages for both sexual and apomictic accessions. Boechera Polyubiquitin 10 was selected as control gene due to its extensive use and proven reliability as a reference control in Boechera [8], Arabidopsis [14] and other plants [36]

Considering instrument background fluorescence, Crossing Point $(\mathrm{Cp})$ is defined as the point at which sample fluorescence rises significantly above the background fluorescence characteristic of a particular detection system, and it is used as a measure for the starting copy numbers of the target gene. For every cDNA, the mean expression level and standard deviation for each set replicate was calculated. In cases where $C p$ values between replicates of the same gene diverged by more than one unit, as measured from cDNAs extracted from micro-dissected tissues, two additional replicates of that particular gene were performed under the same experimental conditions. The corresponding qPCR efficiencies were determined by the Miner algorithm [30]. To quantify gene expression in comparison to a reference gene, the relative expression ratio (R) was determined using the $\Delta \Delta$ Ct method as described by Pfaffl [37]. The obtained $\mathrm{R}$ values for all the genes were transferred into the geNorm program (http://medgen.ugent.be/ jvdesomp/genorm/) for calculation of the expression stability as described by Vandesompele et al. [12]

For validation of the best HKGs, 4 SuperSAGE Tags that had shown reproductive mode-specific expression in cDNA between ovules at the second and fourth developmental stage were selected (see additional file 2). qRT-PCR reactions of cDNA from apomictic and sexual ovules at stages 2 and 4 were performed on an ABIPRISM 7700 HT FAST Real-Time PCR System (Applied Biosystems) with the following cycling profile: $50^{\circ} \mathrm{C}$ for $2 \mathrm{~min}, 95^{\circ} \mathrm{C}$ for $10 \mathrm{~min} ; 40$ cycles of $95^{\circ} \mathrm{C}$ for $15 \mathrm{sec}, 60^{\circ}$ $\mathrm{C}$ for 1 minute. $10 \mu \mathrm{l}$ reactions were performed using the following master mix: $5 \mu \mathrm{l}$ of SYBR I Master Mix buffer, a total of $16.6 \mathrm{pmol}$ for both sense and antisense primers, $2.5 \mu \mathrm{l}$ of water and $1.5 \mu \mathrm{l}$ of cDNA diluted to $0.5 \mathrm{ng}$. Genes of interest and HKGs were run simultaneously in triplicate. For every cDNA, the mean expression level and standard deviation for each set replicate was calculated. The corresponding qPCR efficiencies were determined using the Miner algorithm
[30]. The expression data were normalized according to the REST algorithm using the REST2009 software [34]

\section{Additional material}

Additional file 1: Dissociation curves. Dissociation curves of the 9

Additional file 2: SuperSAGE tags validation. Validation of 4 specifically-expressed SuperSAGE tags from apomictic ovules.

\section{Acknowledgements}

This work was funded by the basic research budget of the Apomixis research group. The authors would like to thank Prof. I. Schubert for valuable comments on the manuscript.

\section{Authors' contributions}

MP was responsible for the experiment, microdissection, sample preparation, bioinformatics analysis of the sequences tested, qRT-PCR assay and drafting the manuscript. MM contributed with tissue isolation, RNA and CDNA sample preparation. SA, JMC and TFS participated as supervisors in the study design, analyses and writing. All authors read and approved the final manuscript.

\section{Competing interests}

The authors declare that they have no competing interests.

Received: 4 May 2011 Accepted: 19 August 2011

Published: 19 August 2011

\section{References}

1. Yang CF, Sun S, Guo Y: Resource limitation and pollen source (self and outcross) affecting seed production in two louseworts, Pedicularis siphonantha and P. longiflora (Orobanchaceae). Botanical Journal of the Linnean Society 2005, 147(1):83-89.

2. Asker SE, Jerling L: Apomixis in plants. CRC; 1992.

3. Aliyu OM, Schranz ME, Sharbel TF: Quantitative variation for apomictic reproduction in the genus Boechera (Brassicaceae). American Journal of Botany 2010, 97(10):1719.

4. Grimanelli D, Leblanc O, Perotti E, Grossniklaus U: Developmental genetics of gametophytic apomixis. Trends in Genetics 2001, 17(10):597-604

5. Spillane C, Curtis MD, Grossniklaus U: Apomixis technology developmentvirgin births in farmers' fields? Nature biotechnology 2004, 22(6):687-691.

6. Morgan R, Ozias-Akins P, Hanna W: Seed set in an apomictic BC 3 pearl millet. International journal of plant sciences 1998, 159(1):89-97.

7. Carman JG: Asynchronous expression of duplicate genes in angiosperms may cause apomixis, bispory, tetraspory, and polyembryony. Biological Journal of the Linnean Society 1997, 61(1):51-94.

8. Sharbel TF, Voigt ML, Corral JM, Thiel T, Varshney A, Kumlehn J, Vogel H, Rotter B: Molecular signatures of apomictic and sexual ovules in the Boechera holboellii complex. The Plant Journal 2009, 58(5):870-882.

9. Sharbel TF, Voigt ML, Corral JM, Galla G, Kumlehn J, Klukas C, Schreiber F, Vogel H, Rotter B: Apomictic and sexual ovules of Boechera display heterochronic global gene expression patterns. The Plant Cell Online 2010, 22(3):655.

10. Jain M, Nijhawan A, Tyagi AK, Khurana JP: Validation of housekeeping genes as internal control for studying gene expression in rice by quantitative real-time PCR. Biochemical and biophysical research communications 2006, 345(2):646-651.

11. Hong SY, Seo PJ, Yang MS, Xiang F, Park CM: Exploring valid reference genes for gene expression studies in Brachypodium distachyon by realtime PCR. BMC Plant Biology 2008, 8(1):112.

12. Vandesompele J, De Preter K, Pattyn F, Poppe B, Van Roy N, De Paepe A, Speleman F: Accurate normalization of real-time quantitative RT-PCR data by geometric averaging of multiple internal control genes. Genome biology 2002, 3(7):34. 
13. Bustin S, Benes V, Nolan T, Pfaffl M: Quantitative real-time RT-PCR-a perspective. Journal of Molecular Endocrinology 2005, 34(3):597.

14. Czechowski T, Stitt M, Altmann T, Udvardi MK, Scheible WR: Genome-wide identification and testing of superior reference genes for transcript normalization in Arabidopsis. Plant physiology 2005, 139(1):5-17.

15. Stürzenbaum SR, Kille P: Control genes in quantitative molecular biological techniques: the variability of invariance. Comparative Biochemistry and Physiology Part B: Biochemistry and Molecular Biology 2001, 130(3):281-289.

16. Dean J, Goodwin P, Hsiang T: Comparison of relative RT-PCR and northern blot analyses to measure expression of 1, 3-glucanase in Nicotiana benthamiana infected with Colltotrichum destructivum. Plant Molecular Biology Reporter 2002, 20(4):347-356.

17. Thomas C, Meyer D, Wolff M, Himber C, Alioua M, Steinmetz A: Molecular characterization and spatial expression of the sunflower ABP1 gene. Plant Molecular Biology 2003, 52(5):1025-1036.

18. Orsel M, Krapp A, Daniel-Vedele F: Analysis of the NRT2 nitrate transporter family in Arabidopsis. Structure and gene expression. Plant physiology 2002, 129(2):886.

19. Ozturk ZN, Talamé V, Deyholos M, Michalowski CB, Galbraith DW, Gozukirmizi N, Tuberosa R, Bohnert HJ: Monitoring large-scale changes in transcript abundance in drought-and salt-stressed barley. Plant Molecular Biology 2002, 48(5):551-573.

20. Silveira ED, Alves-Ferreira M, Guimarães LA, da Silva FR, Carneiro VTC: Selection of reference genes for quantitative real-time PCR expression studies in the apomictic and sexual grass Brachiaria brizantha. BMC Plant Biology 2009, 9(1):84.

21. Thellin O, Zorzi W, Lakaye B, De Borman B, Coumans B, Hennen G, Grisar T, Igout $A$, Heinen E: Housekeeping genes as internal standards: use and limits. Journal of biotechnology 1999, 75(2-3):291-295.

22. Warrington JA, Nair A, Mahadevappa M, Tsygankaya M: Comparison of human adult and fetal expression and identification of 535 housekeeping/maintenance genes. Physiological genomics 2000, 2(3):143.

23. Schmittgen TD, Zakrajsek BA: Effect of experimental treatment on housekeeping gene expression: validation by real-time, quantitative RTPCR. Journal of biochemical and biophysical methods 2000, 46(1-2):69-81.

24. Tricarico C, Pinzani P, Bianchi S, Paglierani M, Distante V, Pazzagli M, Bustin SA, Orlando C: Quantitative real-time reverse transcription polymerase chain reaction: normalization to rRNA or single housekeeping genes is inappropriate for human tissue biopsies. Analytical biochemistry 2002, 309(2):293-300.

25. Böecher T: Cytological and embryological studies in the amphiapomictic Arabis holboellii complex. Kong Dansk Vidensk Selsk Biol Skr; 1951:VI 7:1-57.

26. Naumova TN, van der Laak J, Osadtchiy J, Matzk F, Kravtchenko A, Bergervoet J, Ramulu KS, Boutilier K: Reproductive development in apomictic populations of Arabis holboellii (Brassicaceae). Sexual Plant Reproduction 2001, 14(4):195-200.

27. Windsor AJ, Schranz ME, Formanova N, Gebauer-Jung S, Bishop JG, Schnabelrauch D, Kroymann J, Mitchell-Olds T: Partial shotgun sequencing of the Boechera stricta genome reveals extensive microsynteny and promoter conservation with Arabidopsis. Plant physiology 2006, 140(4):1169.

28. Schranz ME, Windsor AJ, Song B, Lawton-Rauh A, Mitchell-Olds T: Comparative genetic mapping in Boechera stricta, a close relative of Arabidopsis. Plant physiology 2007, 144(1):286.

29. Armstrong SJ, Jones GH: Meiotic cytology and chromosome behaviour in wild type Arabidopsis thaliana. Journal of experimental botany 2003, 54(380):1.

30. Zhao S, Fernald RD: Comprehensive algorithm for quantitative real-time polymerase chain reaction. Journal of Computational Biology 2005, 12(8):1047-1064

31. Andersen $C L$, Jensen JL, Orntoft TF: Normalization of real-time quantitative reverse transcription-PCR data: a model-based variance estimation approach to identify genes suited for normalization, applied to bladder and colon cancer data sets. Cancer Res 2004, 64(15):5245-5250.

32. Silver N, Cotroneo E, Proctor G, Osailan S, Paterson KL, Carpenter GH: Selection of housekeeping genes for gene expression studies in the adult rat submandibular gland under normal, inflamed, atrophic and regenerative states. BMC Mol Biol 2008, 9:64.
33. Van Hiel MB, Van Wielendaele P, Temmerman L, Van Soest $S$, Vuerinckx $K$, Huybrechts R, Broeck JV, Simonet G: Identification and validation of housekeeping genes in brains of the desert locust Schistocerca gregaria under different developmental conditions. BMC Mol Biol 2009, 10:56.

34. Pfaffl MW, Horgan GW, Dempfle L: Relative expression software tool (REST) for group-wise comparison and statistical analysis of relative expression results in real-time PCR. Nucleic Acids Res 2002, 30(9):e36.

35. Altschul SF, Gish W, Miller W, Myers EW, Lipman DJ: Basic local alignment search tool. Journal of molecular biology 1990, 215(3):403-410.

36. Salmona J, Dussert S, Descroix F, de Kochko A, Bertrand B, Joët T: Deciphering transcriptional networks that govern Coffea arabica seed development using combined CDNA array and real-time RT-PCR approaches. Plant Molecular Biology 2008, 66(1):105-124.

37. Pfaffl MW, Tichopad A, Prgomet C, Neuvians TP: Determination of stable housekeeping genes, differentially regulated target genes and sample integrity: BestKeeper-Excel-based tool using pair-wise correlations. Biotechnology letters 2004, 26(6):509-515.

38. Schneitz K, Hülskamp M, Pruitt RE: Wild type ovule development in Arabidopsis thaliana: a light microscope study of cleared whole mount tissue. The Plant Journal 1995, 7(5):731-749.

39. Hardy G, Littlewood J, P G: Inequalities. Cambridge University Press; 2 1988.

40. Kiefer C, Dobes C, Sharbel TF, Koch MA: Phylogeographic structure of the chloroplast DNA gene pool in North American Boechera-A genus and continental-wide perspective. Molecular phylogenetics and evolution 2009, 52(2):303-311.

41. Matzk F, Meister A, Schubert I: An efficient screen for reproductive pathways using mature seeds of monocots and dicots. The Plant Journal 2000, 21(1):97-108.

doi:10.1186/1756-0500-4-303

Cite this article as: Pellino et al:: Selection of reference genes for quantitative real-time PCR expression studies of microdissected reproductive tissues in apomictic and sexual Boechera. BMC Research Notes 2011 4:303.

\section{Submit your next manuscript to BioMed Central and take full advantage of:}

- Convenient online submission

- Thorough peer review

- No space constraints or color figure charges

- Immediate publication on acceptance

- Inclusion in PubMed, CAS, Scopus and Google Scholar

- Research which is freely available for redistribution

Submit your manuscript at www.biomedcentral.com/submit
Ciomed Central 